\title{
Transcranial Doppler Studies in Aneurysm Patients
}

\author{
Kenneth Hutchison and Bryce Weir
}

\begin{abstract}
Fifty patients with ruptured intracranial aneurysms and 8 patients with elective clipping of unruptured aneurysms had daily transcranial Doppler (TCD) measurements performed. The highest mean middle cerebral artery velocity (MCA-Vel) was considered to be the best single parameter for judging a patient's susceptibility to clinically significant vasospasm (VSP). Surgery for the clipping of unruptured aneurysms by itself does not lead to an increase in MCA-Vel. There is a progressive increase in MCA-Vel after subarachnoid hemorrhage (SAH) from aneurysms which peaks between 7 and 10 days. The MCA-Vel is higher on the side of the ruptured aneurysm and the degree of rise is greater if blood is seen on the initial CT scan. It is highly unlikely that a patient whose MCA-Vel remains under $100 \mathrm{~cm} / \mathrm{sec}$ has a degree of angiographic VSP which causes clinical symptomatology. Patients whose MCA-Vel is $>200 \mathrm{~cm} / \mathrm{sec}$ are at great risk of developing clinical symptomatology of VSP and are very likely to have significant angiographic VSP. There is a transitional zone in between these two levels.
\end{abstract}

RÉSUMÉ: Études par doppler transcrânien chez des patients porteurs d'anévrismes Cinquante patients porteurs d'anévrismes intracrâniens rupturés et 8 patients ayant subi un clippage électif d'anévrismes non rupturés ont eu une évaluation quotidienne par Doppler transcrânien. Nous avons estimé que la plus haute vélocité moyenne dans l'artère cérébrale moyenne (MCA-Vel) était le meilleur paramètre individuel pour évaluer la prédisposition d'un patient à développer un vasospasme cliniquement significatif (VSP). En soi, le clippage chirurgical d'un anévrisme non rupturé n'amène pas une augmentation de la MCA-Vel. Il se produit une augmentation progressive de la MCA-Vel à la suite d'une hémorragie subarachnoïdienne $(\mathrm{SAH})$ qui se produit à partir d'un anévrisme, avec un pic entre le septième et le dixième jour. La MCA-Vel est plus grande du côté de l'anévrisme rupturé et le degré d'augmentation est plus considérable si l'épanchement sanguin est visible au CT scan initial. Il est peu probable qu'un patient dont la MCA-Vel demeure sous $100 \mathrm{~cm} / \mathrm{sec}$ ait, à l'angiographie, un VSP qui cause une symptomatologie clinique. Les patients dont la MCA-Vel est $>200 \mathrm{~cm} / \mathrm{sec}$ sont plus à risque de développer une symptomatologie clinique de VSP et sont les plus susceptibles de présenter un VSP significatif à l'angiographie. Il existe une zone de tansition entre ce deux niveaux de MCA-Vel.

Can. J. Neurol. Sci. 1989; 16:411-416

Noninvasive transcranial Doppler ultrasound recording of flow velocity in basal cerebral arteries was introduced to neurosurgery in 1982 by Aaslid and his co-workers. I By placing a range-gated ultrasound Doppler instrument in the temporal area they were able to record the velocity in the middle cerebral artery (MCA-Vel) at a mean of $62 \pm 12 \mathrm{~cm} / \mathrm{sec}$. They predicted that the method would be of particular value in the detection of VSP following SAH. It appears as though their early prediction will be borne out. The advantages of TCD examinations are that they are risk-free and can be performed repetitively on relatively inexpensive equipment. The relative disadvantages are that technical expertise is required for accuracy in the studies.

\begin{abstract}
Methods
Patient Population

Fifty patients with ruptured intracranial aneurysms admitted to hospital acutely following their $\mathrm{SAH}$, and 8 patients having elective clipping of unruptured aneurysms, had daily TCD examinations performed. Examinations were carried out for 21 days or until discharge, whichever came first. Forty-five of the ruptured aneurysm cases were operated in the first day or two following their admission, 3 were operated after a few days with 2 cases admitted in very poor condition who were operated some months later. The percentage of cases in each grade on
\end{abstract}


admission were: $0-14 \%$, I and II $-47 \%$, III and IV $-34 \%$, and $\mathrm{V}-5 \%$. None of the 8 elective cases developed a neurological deficit or died. Of the 27 cases admitted in grade I or II following SAH, 63\% had a good outcome, 33\% had a deficit and $4 \%$ died. The death was in a patient with early massive rebleeding. Of the patients admitted grade III or IV $10 \%$ had a good outcome, $70 \%$ had a deficit and $20 \%$ died. Of patients grade $\mathrm{V}$ on admission, $0 \%$ had a good outcome, $66 \%$ had a deficit and $33 \%$ died. The postoperative mortality rate at 30 days was $2 \%$, there was 1 additional late postoperative death at 4 months to make a total postoperative mortality rate of $4 \%$. All cases received prophylactic albumen to maintain a high normal blood volume and about half the SAH cases received a calcium channel blocker in a study which is still blinded. Symptomatic VSP was treated with hypertension/hypervolemia. Clinical VSP was diagnosed from reviewing the charts retrospectively for delayed clinical deterioration (after day 4 ) not evidently due to some other cause.

\section{Transcranial Doppler Examination}

A $2 \mathrm{MHz}$ pulsed Doppler unit (TC 2-64, Teca Corp., Pleasantville, New York) was used to insonnate the middle, anterior and posterior cerebral and the internal carotid arteries bilaterally through the temporal areas. The usual recording depths from the temporal skin surface were 45 and $55 \mathrm{~mm}$ for distal and proximal middle cerebral, $65 \mathrm{~mm}$ for anterior cerebral, $75-80 \mathrm{~mm}$ for posterior cerebral and $60 \mathrm{~mm}$ for the internal carotid arteries. To locate arteries in addition to the depth change the probe angle was changed slightly, forward for anterior cerebral, backward for posterior cerebral and downward for internal carotid arteries. Slight variation in depth was necessary in some patients. The TCD values were recorded independently of the radiologists who interpreted the angiograms.

In appropriate cases velocity recordings were also made from the basilar artery at depths of 75 and $85 \mathrm{~mm}$ through the foramen magnum area. In all patients velocity recordings from the extracranial carotid arteries were made at an estimated angle of $60^{\circ}$ with the $2 \mathrm{MHz}$ probe at a usual depth of $50 \mathrm{~mm}$.

Mean MCA-Vel only are presented (the mean of the selected waveform not the mean of multiple separate observations).

\section{Statistical Methods}

Data was entered into a computer and the means and standard error of the means were calculated. Data comparison used two-tailed unpaired (pooled variance) t-tests. The total number of patients in each group is indicated in the diagrams, however, the ' $n$ ' on individual days was not constant due to the variation in patient admission to and transfer from the neurosurgical intensive care unit.

\section{Clinical and Radiological Evaluation}

The diagnosis of "clinical VSP" was made on the basis of clinical deterioration more than 4 days from the SAH which could not be explained on some other basis. Angiographic VSP was diagnosed by the radiologist on the basis of the usual radiographic appearance of diffusely narrowed vessels on angiograms which were repeated after the fourth day following SAH. This diagnosis was made without reference to this subsequent study. There was no routine time for performance of repeat angiograms as some were conducted primarily to check on the efficacy of the operative procedure and only a few were performed specifically to evaluate the degree of VSP.

\section{Results}

While on occasions the velocities from the other arteries mirrored the changes in the middle cerebral no additional information was gained from these measurements. Ratio of middle cerebral mean velocity to internal carotid arterial mean velocity was calculated. The variation in this parameter mirrored that of the MCA-Vel but was less stable. The wider fluctuations in the ratio compared to the absolute velocity appeared to be due to variation in apparent internal carotid artery velocity. This was probably due to a difficulty in reproducibly insonnating the artery in the neck at an angle of $60^{\circ}$.

Patients having elective clipping of unruptured aneurysms showed no significant elevation in mean MCA-Vel. These remained in the area of $30-60 \mathrm{~cm} / \mathrm{sec}$ despite the performance of craniotomy and aneurysmal clipping. In contrast, patients after SAH developed a progressive rise in MCA-Vel over the first 7 or 8 days following SAH. By day 8 the mean of all patients had exceeded $100 \mathrm{~cm} / \mathrm{sec}$ (Figure 1).

Patients having blood clot in the subarachnoid space observed on the initial CT had higher MCA-Vel than those whose initial CT did not show blood. However there were no differences between those whose initial CT subarachnoid clot was considered to be "thick" rather than "thin" (Figure 2).

Lateralized aneurysms (excluding anterior communicating or basilar apex locations) showed higher MCA-Vel on the side ipsilateral to the ruptured aneurysm. This difference became apparent after the 4th day. It achieved statistical significance on the 8th and 9th days (Figure 3).

Twenty-seven of the ruptured aneurysm cases had angiograms performed in the period in which VSP occurs. Twenty-one showed severe VSP, 5 showed mild VSP and 1 showed none. The MCA-Vel for the severe cases was higher than the mild or none cases after day 5 post-SAH. Because of

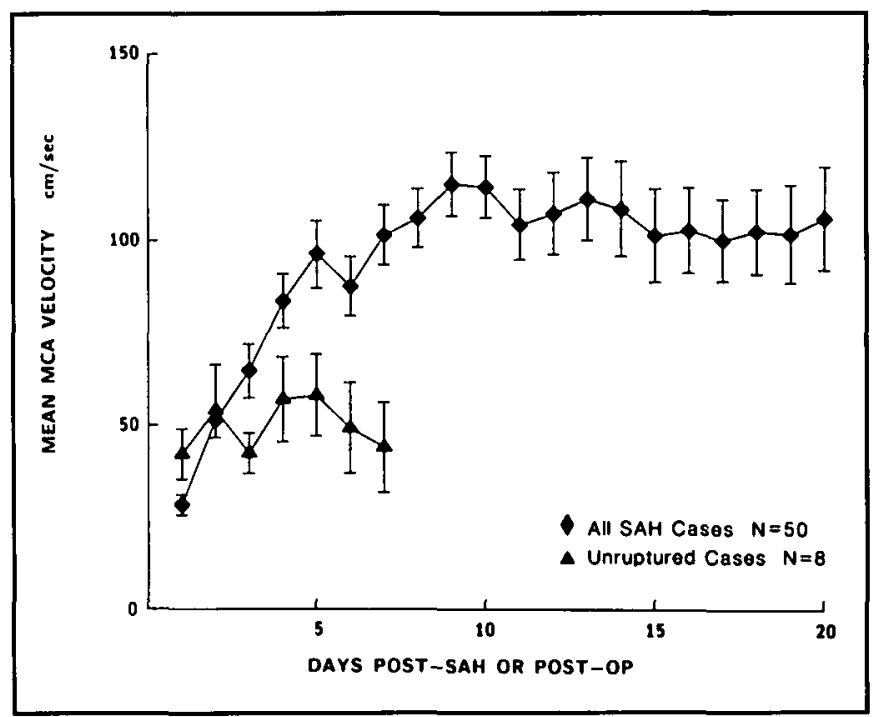

Figure I - Mean MCA-Vel plotted against days post-SAH or post-op in the case of unruptured aneurysms. The average numbers of daily observations $\leq d 5$ were 25 , d6-10 were 41 , dll-15 were $39, d 16-20$ were 25 . 
large individual variation this only achieved statistical significance on day 10. When the highest MCA-Vel for the entire hospital course was plotted for the group with "severe angiographic VSP" versus "mild or no VSP", the mean and standard error of the mean for the "severe" group was $184 \pm 16 \mathrm{~cm} / \mathrm{sec}$ and for the "mild or no" group it was $124 \pm 19 \mathrm{~cm} / \mathrm{sec}$ (not significant). The lowest maximum MCA-Vel in the severe angiographic VSP group was $80 \mathrm{~cm} / \mathrm{sec}$ and the highest MCA-Vel for the mild angiographic VSP group was $205 \mathrm{~cm} / \mathrm{sec}$ (Figure 4). The case with an apparently severe angiographic VSP but low Doppler velocity was of special interest. While the radiological report was "severe, diffuse angiographic spasm" the angiogram on day 13 post-SAH showed a reduction in MCA diameter of only $33 \%$ while the intracranial internal carotid was more reduced at $41 \%$.

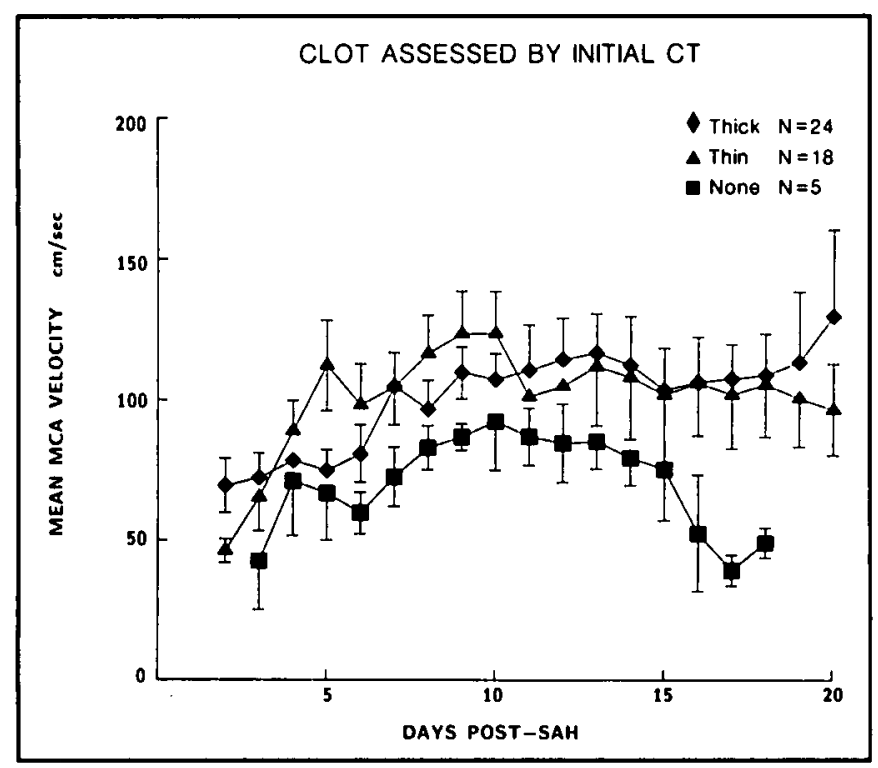

Figure $2-$ Mean MCA.Vel of patients grouped according to findings on initial CT scan plotted against days post-SAH.

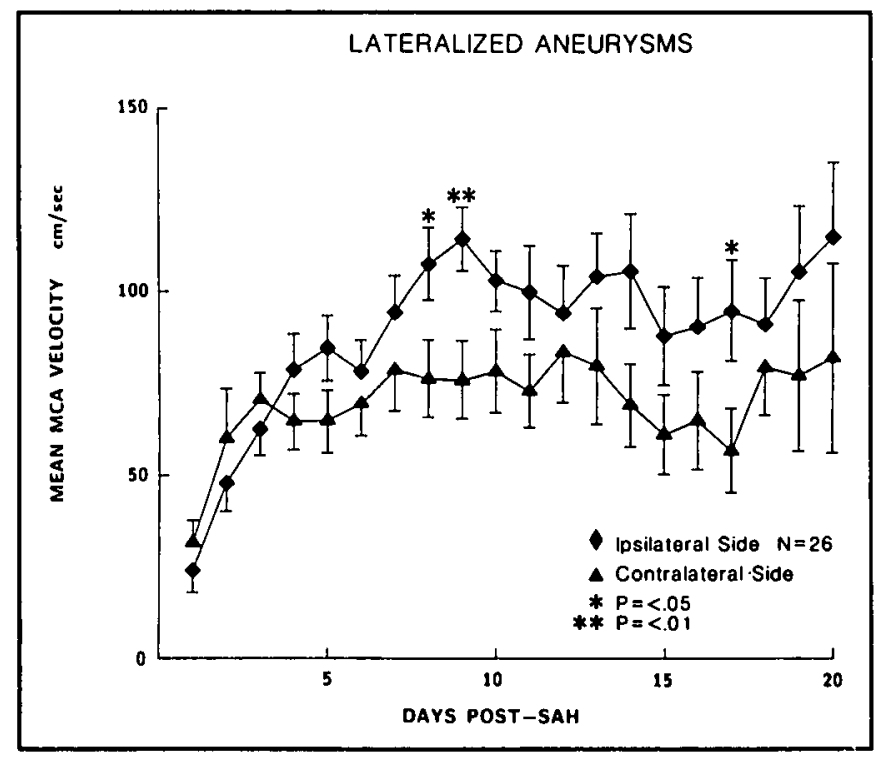

Figure 3 - Mean MCA-Vel plotted against days post-SAH with values grouped by relationship to the ruptured aneurysm - ipsilateral or contralateral.
The actual size of the MCA (which was probably normally on the large size) still looked quite capable of maintaining normal flow (Figure 5), even when florid proximal spasm was evident.

Cases with the diagnosis of "clinical VSP" had higher MCAVel than those who did not but the shape of the curve was similar. After 19 days due to very small numbers the relationship was reversed. The shape of rise in the MCA-Vel curve was similar in both groups. The maximum MCA-Vel was achieved on day 9 in the "clinical VSP" group and on day 10 in the "no clinical VSP" group. The mean of the highest MCA-Vel during the hospital course for each patient with a diagnosis of clinical VSP was plotted. The mean and standard error of the group with "clinical VSP" was $176 \pm 12 \mathrm{~cm} / \mathrm{sec}$. Corresponding figures for the "no clinical VSP" group were $102 \pm 9 \mathrm{~cm} / \mathrm{sec}(\mathrm{p}<.001)$. The lowest MCA-Vel in the "clinical VSP" group was $80 \mathrm{~cm} / \mathrm{sec}$ (Figure 6).

The last Glasgow Coma Score (GCS) recorded for the patient immediately prior to the TCD measurements were recorded. The individual curves varied considerably between patients. There was a tendency for patients with a "flat pattern" for the mean MCA-Vel curves to have high concurrent GCSs. There was also a trend for patients with very high velocity curves to have low GCS. Some other patients showed a "peak pattern" during days 4-12 and there was a slight tendency for the GCS to be lower during the peak than subsequently. There were, however, numerous exceptions to these generalizations.

\section{Discussion}

The results confirm that TCD is an extremely useful technique for monitoring the course of patients with ruptured intracranial aneurysms. Our opinion is that mean MCA-Vel is

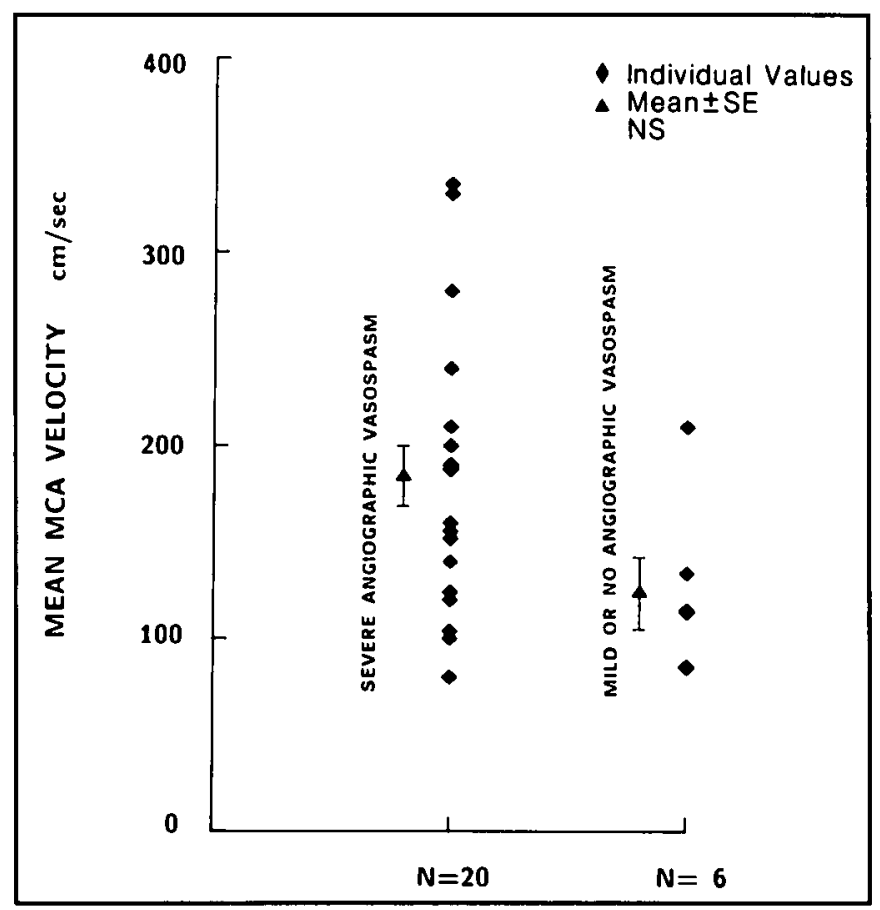

Figure 4 - The highest daily mean MCA.Vel for each case with severe angiographic vasospasm and with no or mild angiographic vasospasm. The means of the two groups are not significantly different. 


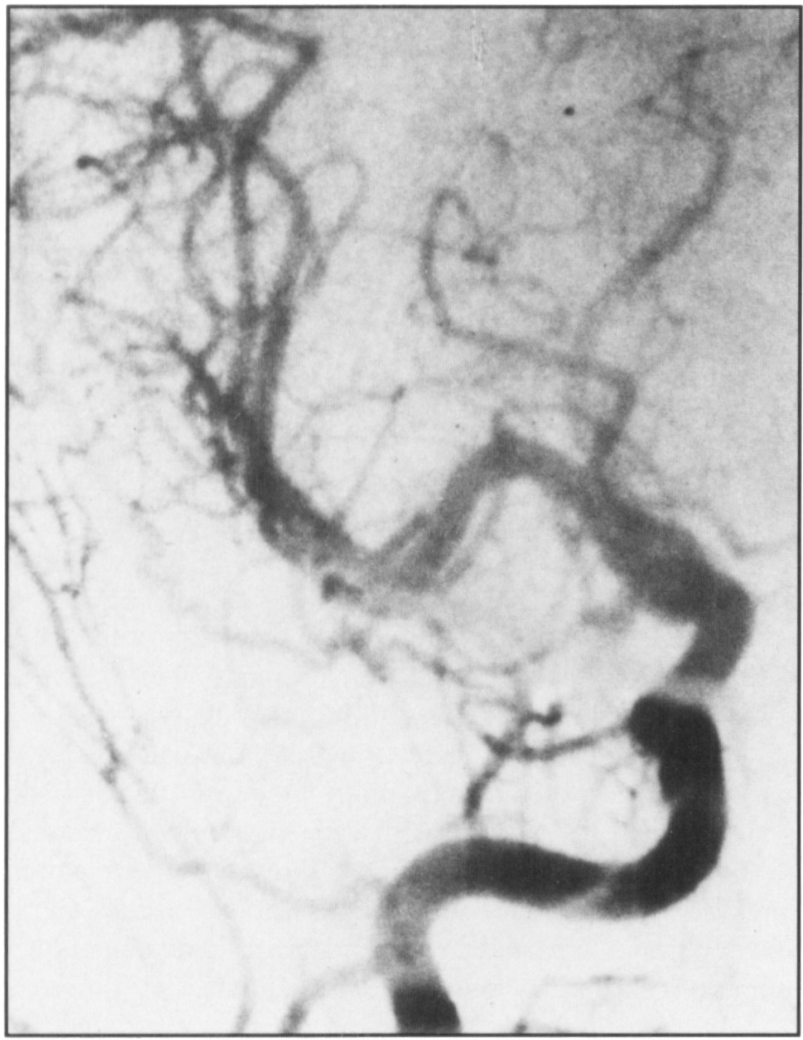

A

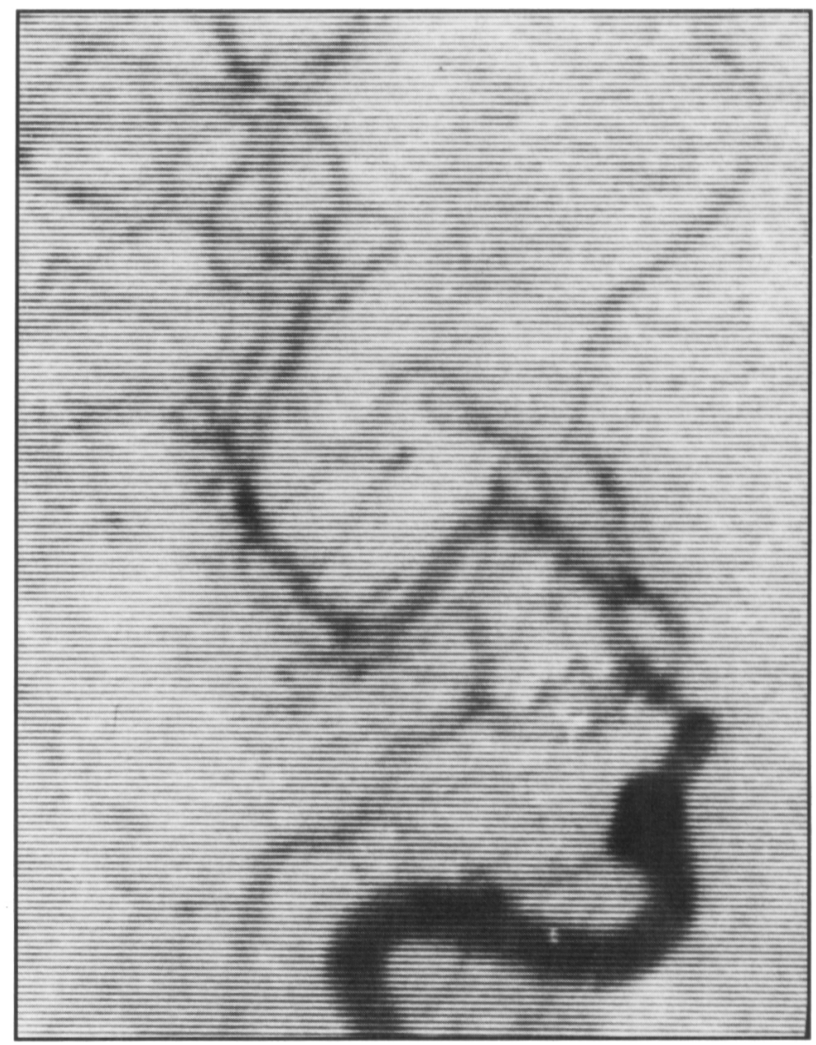

B

Figure 5-A-anteroposterior view of the right carotid circulation, day I post-SAH. B - same view of the right carotid circulation, day I3 postSAH. The contemporary radiological report was "severe, diffuse vasospasm" but the MCA-Vel remained $<100 \mathrm{~cm} / \mathrm{sec}$ throughout. In retrospect the degree of VSP of the MCA did not appear too threatening. This was the only case of angiographic VSP (independently diagnosed by a neuroradiologist) with a low MCA-Vel.

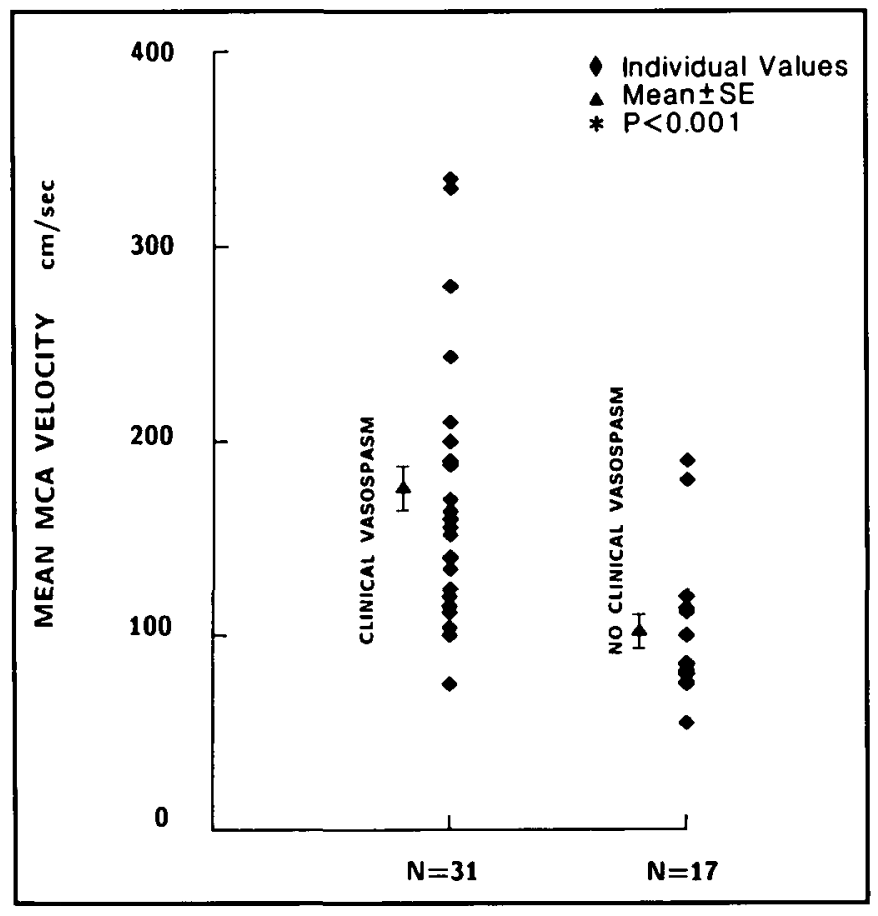

Figure 6-The highest daily mean MCA-Vel for each case with diagnosis of clinical VSP or no clinical VSP. The difference was highly significant. Many of these symptomatic episodes were transient. the most useful single parameter in this type of analysis for patients with ruptured supratentorial aneurysms.

Aaslid et $\mathrm{al}^{2}$ studied 18 cases of SAH from aneurysm. The mean MCA-Vel for studies done in the first 4 days following $\mathrm{SAH}$ was $84 \pm 18 \mathrm{~cm} / \mathrm{sec}$ in 8 patients. The corresponding diameters of the MCA in concurrently performed angiographic studies were $2.7 \pm 0.3 \mathrm{~mm}$. Ten patients had studies performed between days 5 and 12 and the MCA-Vel were $109 \pm 45$ and the concurrent MCA diameters $2.1 \pm 0.6 \mathrm{~mm}$. Angiographically diagnosed VSP in the MCA was associated with MCA-Vel $>120-130 \mathrm{~cm} / \mathrm{sec}$. Seiler and Aaslid ${ }^{3}$ presented data on 39 patients with SAH from ruptured aneurysm. In the 20 patients with normal outcomes, $75 \%$ had MCA-Vel $<140 \mathrm{~cm} / \mathrm{sec} ; 10 \%$ $140-200 \mathrm{~cm} / \mathrm{sec}$ and $15 \%>200 \mathrm{~cm} / \mathrm{sec}$. For 11 patients with reversible delayed ischemic deficits (DID) the corresponding values were $27 \%<140 \mathrm{~cm} / \mathrm{sec} ; 36 \% \quad 140-200 \mathrm{~cm} / \mathrm{sec}$; and $36 \%$ $>200 \mathrm{~cm} / \mathrm{sec}$. None of the 8 patients with infarction associated with the delayed ischemic deficit had MCA-Vel $<140 \mathrm{~cm} / \mathrm{sec}$; $13 \%$ had velocities $140-200 \mathrm{~cm} / \mathrm{sec}$ and fully $88 \%$ had velocities exceeding $200 \mathrm{~cm} / \mathrm{sec}$. In the patients with symptomatic VSP who were operated on after day 10 , the maximum velocities were reached between days 7-12. There were examples of asymptomatic patients with velocities $>200 \mathrm{~cm} / \mathrm{sec}$. Velocities in the range of $120-140 \mathrm{~cm} / \mathrm{sec}$ were never associated with infarction.

Twelve cases of SAH from ruptured aneurysms were studied by Compton et $\mathrm{al}^{4}$ using TCD and $\mathrm{Xe}^{133}$ cerebral blood flow 
studies. In their material MCA-Vel $>100 \mathrm{~cm} / \mathrm{sec}$ were associated with angiographic VSP in $80 \%$ of cases. For patients with velocities $<100 \mathrm{~cm} / \mathrm{sec}$, only $10 \%$ had angiographic VSP. The quotient of the cerebral blood flow $\left(\mathrm{Xe}^{133}\right)$ over the MCA-Vel $(\mathrm{cm} / \mathrm{sec})$ correlated better with the clinical grade of the patients than either the cerebral blood flow alone or the MCA-Vel alone.

Fifty cases of ruptured aneurysms were studied by Harders and Gilsbach. 5 They established that the MCA-Vel increased to approximately day 7 . The maximum velocities were present between days 11 and 20 . Perhaps the apparent continued high velocities to a time when patients usually appear to have recovered from VSP, which was also evident in our data, is due to the selective sampling of the most sick patients while TCD is not as likely to be done on those who have recovered and gone home. There was an inverse relationship between velocity and angiographic diameter of the MCA and intracranial internal carotid but not the proximal anterior cerebral. MCA-Vel varied with the source of the hemorrhage (site of the ruptured aneurysm), side of the operation and use of intravenous nimodipine (velocity was lowered). Fourteen percent of their patients developed reversible DID but only $2 \%$ died from VSP. DID occurred in the interval between the 6 th and 12 th days at which time the MCAVel were $>137 \mathrm{~cm} / \mathrm{sec}$. All patients with DID had MCA-Vel $>117 \mathrm{~cm} / \mathrm{sec}$. This value was exceeded on day 3 or 4 . In their opinion an increase of $>20 \mathrm{~cm} / \mathrm{sec}$ between days 3 and 7 was indicative of impending DID.

Sekhar et $\mathrm{al}^{6}$ had 21 cases. Eight of these developed a DID and had reduction in cerebral blood flow demonstrated with the stable Xe-CT method. MCA-Vel were significantly elevated in their cases between days 4 and 12. The VSP group ( 8 patients) had mean MCA-Vel of $199 \pm 27 \mathrm{~cm} / \mathrm{sec}$ while the 13 cases without VSP had significantly lower velocities $(121 \pm 5 \mathrm{~cm} / \mathrm{sec})$. When the cerebral blood flow was $<20 \mathrm{ml} / 100 \mathrm{gm} / \mathrm{min}$ the basal vessels all showed extreme levels of increased velocities by TCD examination.

Seiler et al ${ }^{7}$ analyzed data from 118 patients with ruptured aneurysms having TCD examinations between days 3 and 10 post-SAH. MCA-Vel were $<80 \mathrm{~cm} / \mathrm{sec}$ in $5 \% ; 80-140 \mathrm{~cm} / \mathrm{sec}$ in $43 \% ; 140-200 \mathrm{~cm} / \mathrm{sec}$ in $32 \%$ and $>200 \mathrm{~cm} / \mathrm{sec}$ in $20 \%$ of cases. No significant difference in MCA-Vel was observed between cases operated in $<4$ days following SAH or in the interval 6-30 days post-SAH. Like most workers they concluded that the mean value for MCA-Vel is more useful than the peak value. Additionally, because the MCA carries about $80 \%$ of the hemispheric blood flow and because it is more of an end artery than the proximal anterior cerebral, the reductions associated with VSP are more eloquently demonstrated by MCA values than proximal anterior cerebral or posterior cerebral values.

Bishop et al ${ }^{8}$ measured MCA-Vel in 17 symptomatic patients with a variety of illnesses and compared these with measurements of ipsilateral hemispheric blood flow measured by the intravenous $\mathrm{Xe}^{133}$ technique. Measurements were made at rest and during hypercapnia. The absolute measurements of MCAVel and hemispheric CBF showed poor correlation because of wide variations at rest between patients but the blood flow response to hypercapnia and the increased velocity response to hypercapnia (both expressed as a reactivity index) showed a good correlation. They concluded that changes in MCA-Vel reli- ably correlated with changes in CBF but absolute velocity could not be used as an indicator of CBF. Lindegaard and co-workers ${ }^{9}$ measured MCA-Vel during periods of transient, rapid blood flow variations in 7 patients having extracranial carotid surgery. The extracranial internal carotid blood flow was measured by flow meters at the time of external carotid occlusion and Doppler recording. The mean internal carotid artery flow varied from $167-399 \mathrm{ml} / \mathrm{min}$ and the mean MCA-Vel varied from 32 $78 \mathrm{~cm} / \mathrm{sec}$. The relation between flow volume and blood velocity were nearly linear under the experimental conditions. Seventy-one patients suffering from intracranial hypertension with subsequent brain death were studied using TCD by Hassler et al. 10 Twenty-nine of these patients were assessed by arterial and intracranial pressure measurements, 33 also had four vessel angiograms. With increasing intracranial pressure, the Doppler wave forms exhibited characteristic changes with a progressive lowering of the diastolic part of the velocity curve which ultimately became 0 and then reversed as the intracranial pressure progressively climbed. Following a point of diastolic reversal in the Doppler wave form, all flow except for a small systolic peak ceased and ultimately these also disappeared as intracranial pressure exceeded arterial pressure. DeWitt and Wechsler'l suggested several pitfalls in the diagnosis of VSP by TCD. They considered that narrowing of branches distal to the proximal segments of the anterior cerebral artery or posterior cerebral artery will usually be beyond the focal range of the Doppler probe and difficult to detect. They observed that changes in the shape of the trace and proximal arteries occurred only if the distal VSP is extensive. Severe VSP of the internal carotid artery may be of sufficient degree to diminish distal flow and thereby decrease velocity in the basal cerebral arteries. This could result in falsely low velocities when VSP coexists in the proximal intracranial or cranial and extracranial carotid basal vessels as well as in the subarachnoid space. In the author's experience sufficiently severe narrowing of distal branches (such as the M2 or $\mathrm{M} 3$ portions of the $\mathrm{MCA}$ ) in the absence of proximal VSP is exceedingly rare so this is unlikely to be a common problem.

Our own data is consistent with what has previously been noted in the literature. The wide variation in values between different patients probably reflects a variety of anatomical, hemodynamic and rheological influences in addition to a diffuse narrowing of the major conducting vessels when VSP is present. The gradual rise in velocity in the first few days probably reflects the time course of the development of VSP as more spasmogens are released from the lysis of trapped erythrocytes. Probably after 7-10 days the level of vasoconstrictors is stable or falling.

The initial world experience suggests that angiographic VSP which is of a severe degree and involves the middle cerebral arteries is almost certain to be associated with increased MCAVel. From a practical point of view if the MCA-Vel is $<100 \mathrm{~cm} / \mathrm{sec}$ then the chance of clinically significant angiographic VSP being present is minimal. At rates above $120 \mathrm{~cm} / \mathrm{sec}$ very close observation is required. If the MCA-Vel is above $200 \mathrm{~cm} / \mathrm{sec}$, severe VSP is almost certainly present and it is very likely to be clinically significant. At that point, if not before, vigorous steps should be taken to prevent ischemia subsequent to the VSP. To some extent TCD may replace angiogra- 
phy as the diagnostic technique of choice for postoperative VSP in centers having experienced and readily available ultrasonographers.

\section{ACKNOWLEDGEMENTS}

The authors wish to express their sincere gratitude to the technical staff who performed the TCD examination - Kathy Henderson, Myrna Mata and Mary Lou Weir. This work was made possible by a grant from the Special Services and Research Committee of the University of Alberta Hospitals.

\section{REFERENCES}

1. Aaslid R, Markwalder T, Nornes H. Noninvasive TCD ultrasound recording of flow velocity in basal cerebral arteries. J Neurosurg 1982; 57: 769-774.

2. Aaslid R, Huber P, Nornes $H$. Evaluation of cerebrovascular spasm with TCD ultrasound. J Neurosurg 1984; 60: 37-41.

3. Aaslid R. Transcranial Doppler Sonography. New York, SpringerVerlag, 1986; 177.

4. Compton JS, Redmond S, Symon L. Cerebral blood velocity in SAH: a TCD study. J Neurol Neurosurg Psychiatry 1987; 50: 1499-1503
5. Harders AG, Gilsbach JM. Time course of blood velocity changes related to VSP in the circle of Willis measured by TCD ultrasound. J Neurosurg 1987; 66: 718-728.

6. Sekhar LN, Wechsler LR, Yonas H, et al. Value of TCD examination in the diagnosis of cerebral VSP after SAH. Neurosurgery 1988; 22: 813-821.

7. Seiler RW, Reulen HJ, Huber P, et al. Outcome of aneurysmal SAH in a hospital population: a prospective study including early operation, intravenous Nimodipine, and TCD ultrasound. Neurosurgery 1988; 23: 598-604.

8. Bishop CCR, Powell S, Rutt D, et al. Transcranial Doppler measurement of middle cerebral artery blood flow velocity; a validation study. Stroke 1986; 17: 913-915.

9. Lindegaard K-F, Lundar T, Wilbert $J$, et al. Variations in middle cerebral artery blood flow investigated with noninvasive transcranial blood velocity measurements. Stroke 1987; 18: 1025 1030.

10. Hassler W, Steinmetz H, Gawlowski J. Transcranial Doppler ultrasonography in raised intracranial pressure and in intracranial circulatory arrest. J Neurosurg 1988; 68: 745-75I.

11. DeWitt LD, Wechsler LR. Transcranial Doppler. Stroke 1988; 19: 915-921. 